$$
\text { CONF. } 960252--4
$$

\section{Power Consumption and Byproducts in Electron Beam and Electrical Discharge Processing of Volatile Organic Compounds}

B. M. Penetrante, M. C. Hsiao, J. N. Bardsley

B. T. Merritt, G. E. Vogtlin, P. H. Wallman

Lawrence Livermore National Laboratory, Livermore, CA

A. Kuthi, C. P. Burkhart, J. R. Bayless

First Point Scientific, Inc., Agoura Hills, CA
RECENEO

MAAV 16 1996

OSTI

This paper was prepared for submittal to:

Second International Symposium on

Environmental Applications of Advanced Oxidation Technologies San Francisco, CA

February 28 - March 1, 1996

February 20, 1996

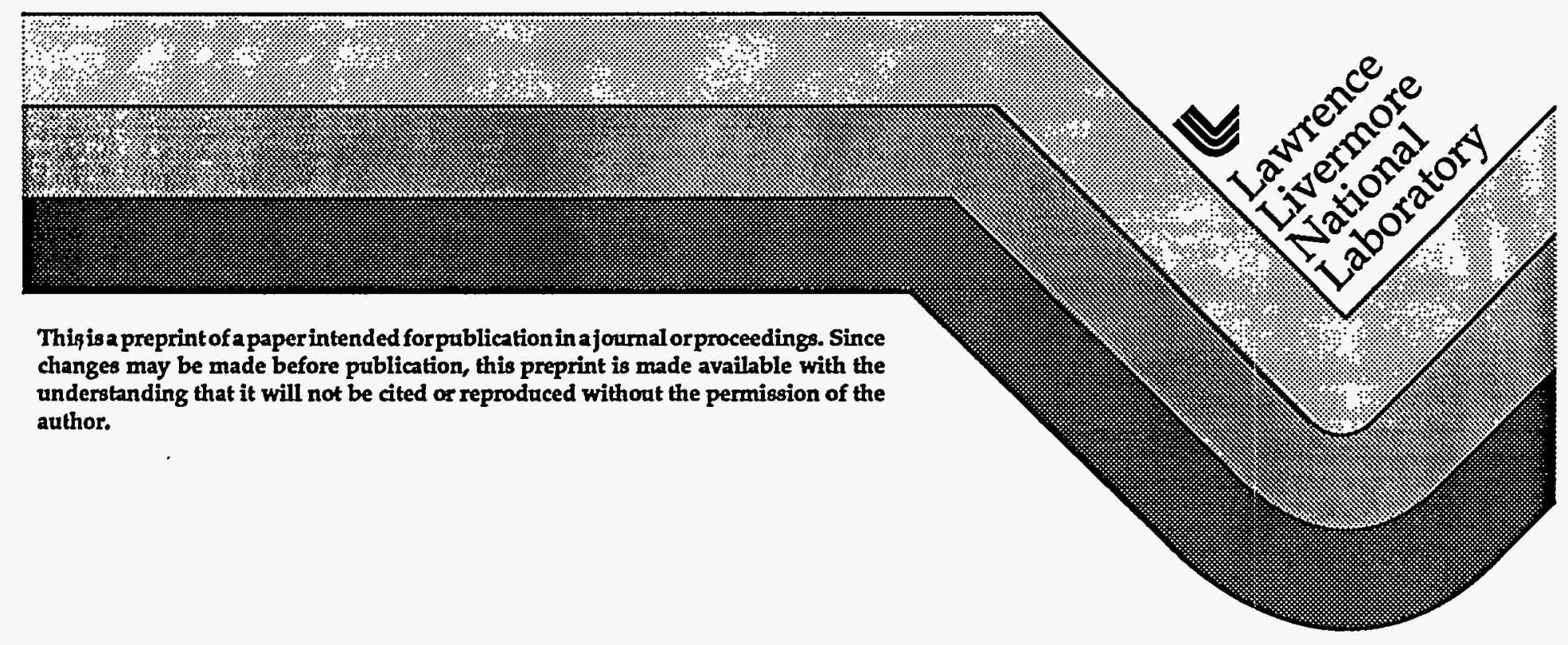




\section{DISCLAIMER}

This document was prepared as an account of work sponsored by an agency of the United States Government. Neither the United States Government nor the University of California nor any of their employees, makes any warranty, express or implied, or assumes any legal liability or responsibility for the accuracy, completeness, or usefulness of any information, apparatus, product, or process disclosed, or represents that its use would not infringe privately owned rights. Reference herein to any specific commercial product, process, or service by trade name, trademark, manufacturer, or otherwise, does not necessarily constitute or imply its endorsement, recommendation, or favoring by the United States Government or the University of California. The views and opinions of authors expressed herein do not necessarily state or reflect those of the United States Government or the University of California, and shall not be used for advertising or product endorsement purposes. 


\section{DISCEAUTER}

Portions of this doctment may be illegible: in electronic inage products. Images are produced-from-the best ayailable original document: 
Second International Symposium on

Environmental Applications of Advanced Oxidation Technologies

San Francisco, February 28 - March 1, 1996

\title{
POWER CONSUMPTION AND BYPRODUCTS IN ELECTRON BEAM AND ELECTRICAL DISCHARGE PROCESSING OF VOLATILE ORGANIC COMPOUNDS
}

\author{
B. M. Penetrante, M. C. Hsiao, J. N. Bardsley, \\ B. T. Merritt, G. E. Vogtlin and P. H. Wallman \\ Lawrence Livermore National Laboratory, Livermore, California 94550
}

A. Kuthi, C. P. Burkhart and J. R. Bayless

First Point Scientific, Inc., Agoura Hills, California 91301

\begin{abstract}
Among the new methods being investigated for the post-process reduction of volatile organic compounds (VOCs) in atmospheric-pressure air streams are based on non-thermal plasmas. Electron beam, pulsed corona and dielectric-barrier discharge methods are among the more extensively investigated techniques for producing non-thermal plasmas. In order to apply non-thermal plasmas in an industrial scale, it is important to establish the electrical power requirements and byproducts of the process. In this paper we present experimental results using a compact electron beam reactor, a pulsed corona and a dielectric-barrier discharge reactor. We have used these reactors to study the removal of a wide variety of VOCs. The effects of background gas composition and gas temperature on the decomposition chemistry have been studied. We present a description of the reactions that control the efficiency of the plasma process. We have found that pulsed corona and other types of electrical discharge reactors are most suitable only for processes requiring $O$ radicals. For VOCs requiring copious amounts of electrons, ions, $\mathrm{N}$ atoms or $\mathrm{OH}$ radicals, the use of electron beam reactors is generally the best way of minimizing the electrical power consumption. Electron beam processing is remarkably more effective for all of the VOCs we tested. For control of VOC emissions from dilute, large volume sources such as paint spray booths, cost analysis shows that the electron beam method is cost-competitive to thermal and catalytic methods that employ heat recovery or hybrid techniques.
\end{abstract}

\section{INTRODUCTION}

Volatile organic compounds (VOCs) are emitted from numerous manufacturing processes. In most of these processes, either for raw materials, intermediates, or finished products, VOC-containing materials are present as 
chemicals, solvents, release agents, coatings, and decomposition products that eventually must be disposed of.

The control of VOC emissions from dilute, large volume sources such as paint spray booths is a challenging problem. Conventional technologies, such as carbon adsorption/solvent recovery or catalytic/thermal oxidation have high annual costs per ton of VOC emissions controlled. With a large gas flow rate $(50,000$ to $250,000 \mathrm{cfm}$ ) and low solvent concentrations (100 ppm or less) of no possible reuse value, operating costs for conventional systems over five years can greatly exceed the installed capital cost.

In order to reduce the operating cost, novel low-temperature (ambient to $125^{\circ} \mathrm{C}$ ) treatment technologies are being sought. The emerging technologies include low-temperature catalysts, biofiltration and non-thermal plasmas. Catalysts easily suffer from plugging, fouling or poisoning by particulates and non-VOC materials in the exhaust stream (Ref. 1); this results in high maintenance costs. The major disadvantage of biofilters is their large specific footprint, typically 100-400 square feet per 1,000 cfm of treated gas (Ref. 2). Biofilter systems and filter materials may also require costly maintenance and replacement.

Non-thermal plasma processing is an emerging technology for the abatement of dilute concentrations of VOCs (Ref. 3). Either electrical discharge or electron beam methods can produce these plasmas. The basic principle that these techniques have in common is to produce a plasma in which a majority of the electrical energy goes into the production of energetic electrons, rather than into gas heating. Through electron-impact dissociation and ionization of the background gas molecules, the energetic electrons produce free radicals, ions and additional electrons which, in turn, oxidize, reduce or decompose the pollutant molecules. This is in contrast to the use of plasma furnaces or torches and several chemical techniques in which the whole gas is heated in order to break up the undesired molecules.

Electrical discharge and electron beam methods can both be implemented in many ways. There are many types of electrical discharge reactors, the variants depending on the electrode configuration and electrical power supply (pulsed, AC or DC). Some of the types of electrical discharge reactors that have been investigated for VOC abatement include the pulsed corona (Refs. 4-5), ferroelectric packed bed (Ref. 4), dielectric-barrier discharge (Refs. 5-8), surface discharge (Ref. 9), gliding arc (Ref. 10) and microwave discharge (Ref. 11). Two of the more extensively investigated types of discharge reactors are based on the pulsed corona and dielectricbarrier discharge. In the pulsed corona method, the reactor is driven by very short pulses of high voltage, thus creating short-lived discharge plasmas that consist of energetic electrons, which in turn produce the free radicals responsible for the decomposition of the undesirable molecules. In a dielectric barrier discharge reactor, one or both of the electrodes are covered with a dielectric layer, such as glass or alumina. Whereas in the pulsed corona method the transient behavior of the plasma is controlled by the applied voltage pulse, the plasma that takes place in a dielectric-barrier discharge self-extinguishes when charge build-up on the dielectric layer reduces the local electric field. Dielectric-barrier discharge reactors, also referred to as silent discharge reactors, are now routinely used to produce commercial 
quantities of ozone. Unfortunately, the plasma conditions suitable for the generation of ozone are not the same plasma conditions optimum for the destruction of most VOCs.

The electron beam method has been applied to the removal of vinyl chloride (Ref. 12), trichloroethylene (Refs. 13-15), trichloroethane (Ref. 15), carbon tetrachloride (Refs. 16-18) and other types of volatile hydrocarbons encountered in industrial off-gases (Refs. 18-19). In the past, the high capital cost and $x$-ray hazard associated with conventional MeV-type electron beam accelerators have discouraged the use of electron beam processing in many pollution control applications. Recently, however, compact low-energy $(<200 \mathrm{keV})$ electron accelerators have been developed to meet the requirements of industrial applications such as crosslinking of polymer materials, curing of solvent-free coatings, and drying of printing inks. Special materials have also been developed to make the window thin and rugged. Some of these compact electron beam sources are already commercially available and could be utilized for many pollution control applications.

In this paper we will present a comparative assessment of various nonthermal plasma reactors. The thrust of our work has been two-fold: (1) to understand the scalability of various non-thermal plasma reactors by focusing on the energy efficiency of the electron and chemical kinetics, and (2) to identify the byproducts to ensure that the effluent gases from the processor are either benign or much easier and less expensive to dispose of compared to the original pollutants. We will present experimental results using a compact electron beam reactor, pulsed corona reactor and dielectric-barrier discharge. We have used these reactors to study the removal of a wide variety of VOCs. We have studied the effects of background gas composition and gas temperature on the decomposition chemistry: For all of the pollutants investigated, we find that electron-beam processing is remarkably more energy efficient than pulsed corona or dielectric-barrier discharge processing. Preliminary cost analysis based on these data show that the electron beam method is cost-competitive to advanced thermal and catalytic methods that employ heat recovery or hybrid techniques.

\section{TEST FACILITY}

All of our experiments were performed in a flow-through configuration. To characterize the energy consumption of the process for each VOC, the composition of the effluent gas was recorded as a function of the input energy density. The input energy density, Joules per standard liter, is the ratio of the power (deposited into the gas) to gas flow rate at standard conditions $\left(25^{\circ} \mathrm{C}\right.$ and $\left.1 \mathrm{~atm}\right)$. The amount of VOC was quantified using an FTR analyzer and a gas chromatograph.

Our electron beam reactor, shown schematically in Figure 1, used a cylindrical electron gun designed to deliver a cylindrically symmetric electron beam that is projected radially inward through a $5 \mathrm{~cm}$ wide annular window into a $17 \mathrm{~cm}$ diameter flow duct. An electron beam of $125 \mathrm{keV}$ energy was introduced into the reaction chamber through a 0.7 mil thick titanium window. The electron beam current was produced from a low-pressure helium plasma in an annular vacuum 
chamber surrounding the flow duct. This novel design facilitates highly uniform (efficient) irradiation of the flowing gas. The non-plasma produced by the electron beam is capable of decomposing the VOCs in polluted gas streams at high flow rates.

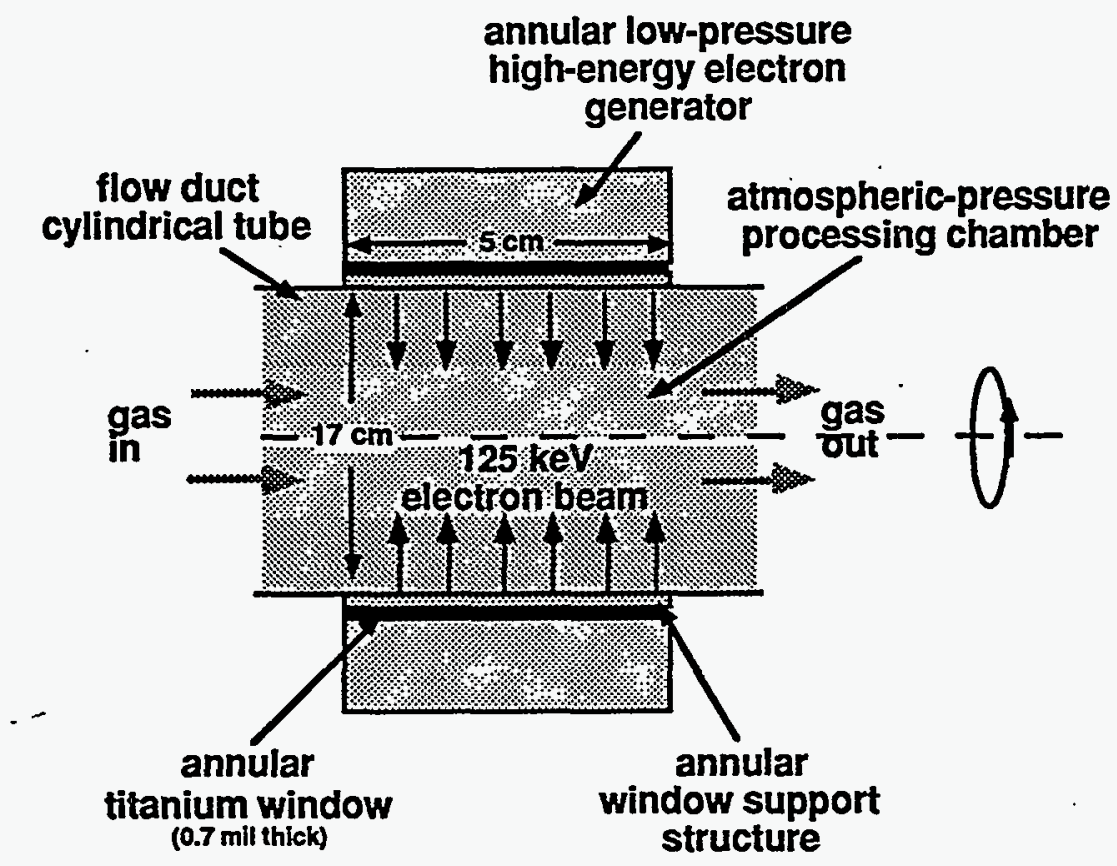

Figure 1. Schematic of the compact electron beam reactor developed by First Point Scientific, Inc. The cylindrical electron gun is designed to deliver a cylindricallysymmetric highly-uniform electron beam that is projected radially inward into the gas flow duct.

Our pulsed corona reactor is a $1.5 \mathrm{~mm}$ diameter wire in a $60 \mathrm{~mm}$ diameter metal tube $300 \mathrm{~mm}$ long. The power supply is a magnetic pulse compression system capable of delivering up to $15-35 \mathrm{kV}$ output into $100 \mathrm{~ns}$ FWHM pulses at repetition rates from $15 \mathrm{~Hz}$ to $1.5 \mathrm{kHz}$. The power input to the processor was varied by changing either the pulse energy or pulse repetition frequency. For the same energy density input, either method produced almost identical results. The gas mixtures were set with mass flow controllers. The gas and processor temperatures can be maintained at a temperature that can be controlled from $25^{\circ} \mathrm{C}$ to $300^{\circ} \mathrm{C}$.

We investigated whether it is possible to improve the processing efficiency by taking advantage of transient high electric fields during the formation of the streamer plasma. To do this, the voltage pulse should be very fast-rising, but with a pulse length short enough so that most of the radical production occurs only during streamer propagation. One way of achieving this condition is by combining the fastrising, strongly non-uniform applied electric field of a corona reactor with the selfextinguishing microdischarge pulses of a dielectric-barrier discharge reactor. We therefore used a reactor that is a form of hybrid between a pulsed corona reactor and a dielectric-barrier discharge reactor. The reactor consisted of a wire $(1.5 \mathrm{~mm}$ 
diameter) in a $300 \mathrm{~mm}$ long dielectric (alumina) tube with inner and outer diameters of $28 \mathrm{~mm}$ and $35 \mathrm{~mm}$, respectively. The middle $150 \mathrm{~mm}$ of the dielectric tube has aluminum foil coating the outside to form the outer electrode.

\section{RESULTS AND. DISCUSSION}

Whatever the type of reactor, the plasma can induce three basic types of reactions with the VOC molecules, as shown in Figure 2. The electron mean energy in a plasma reactor is very important because it determines the types of radicals produced in the plasma and the input electrical energy required to produce those radicals. Figure 3-(a) shows the dissipation of the input electrical power in a dry air discharge. Note that at low electron mean energies $(<5 \mathrm{eV})$ a large fraction of the input electrical energy is consumed in the vibrational excitation of $\mathrm{N}_{2}$. Electron mean energies around $5 \mathrm{eV}$ are optimum for the electron-impact dissociation of $\mathrm{O}_{2}$, which is important for the production of $O$ radicals. These oxidizing radicals play a key role in the generation of ozone and the initial decomposition of some types of VOCs. For VOCs that take advantage of electron-induced or ion-induced decomposition, high electron mean energies are required to efficiently implement the ionization of the background gas.

The rate coefficients for electron-impact dissociation and ionization reactions strongly depend on the electron energy distribution in the plasma. In pulsed corona and dielectric-barrier discharge reactors, the non-thermal plasma is produced through the formation of statistically distributed microdischarges. The electrons dissociate and ionize the background gas molecules within nanoseconds in the narrow channel formed by each microdischarge. The electron energy distribution in the plasma is complicated because the electric field is strongly non-uniform (e.g. because of strong space-charge field effects) and time dependent. However, most of the species responsible for the chemical processing are generated in the microdischarge channels already established during the main current flow. In each microdischarge column, the electrons acquire a drift velocity, $v_{d}$, and an average energy corresponding to an effective $\mathrm{E} / \mathrm{n}$, i.e., the value of the electric field $\mathrm{E}$ divided by the total gas density $n$. The efficiency for a particular electron-impact process can be expressed in terms of the G-value (number of dissociation or ionization reactions per $100 \mathrm{eV}$ of input energy) defined as

$$
\mathrm{G} \text {-value }=100 \mathrm{k} /\left(\mathrm{v}_{\mathrm{d}} \mathrm{E} / \mathrm{n}\right)
$$

where $k$ is the rate coefficient $\left(\mathrm{cm}^{3} /\right.$ molec-s). The rate coefficient $k$ represents the number of reactions in a unit volume per unit time. The quantity $v_{d} E / n$ represents the amount of energy expended by the electrons in a unit volume per unit time. In Figure 3-(b) the calculated G-values for various electron-impact dissociation and ionization processes in dry air are shown as functions of the electron mean energy in the discharge plasma.

Under most conditions encountered in pulsed corona or dielectric-barrier discharge processing, the effective $\mathrm{E} / \mathrm{n}$ is close to the value for breakdown (Paschen field) (Refs. 20-21). For dry air, the effective $\mathrm{E} / \mathrm{n}$ is around $130 \mathrm{Td}\left(1 \mathrm{Td}=10^{-17} \mathrm{~V}\right.$ $\mathrm{cm}^{2}$ ), which corresponds to an electron mean energy of about $4 \mathrm{eV}$. This analysis 
suggests that the attainable electron mean energy in electrical discharge reactors is rather limited and cannot be significantly enhanced by changing the electrode configuration or voltage pulse parameters.

$$
\begin{gathered}
\text { Radical-induced decomposition } \\
e+\mathrm{O}_{2} \rightarrow \mathrm{e}+\mathrm{O}(\mathrm{P} \mathrm{P})+\mathrm{O}\left({ }^{1 D}\right) \\
\mathrm{O}\left({ }^{3} \mathrm{P}\right)+\mathrm{CCl}_{4} \rightarrow \mathrm{ClO}+\mathrm{CCl}_{3} \\
\mathrm{O}\left({ }^{1} \mathrm{D}\right)+\mathrm{H}_{2} \mathrm{O}+\mathrm{OH}+\mathrm{OH} \\
\mathrm{OH}+\mathrm{CCl}_{4} \rightarrow \mathrm{HOCl}+\mathrm{CCl}_{3} \\
\left.e+\mathrm{N}_{2} \rightarrow \mathrm{e}+\mathrm{N}^{4} \mathrm{~S}\right)+\mathrm{N}\left({ }^{2} \mathrm{D}\right) \\
\mathrm{N}(4 \mathrm{~S})+\mathrm{CH}_{2} \mathrm{Cl}_{2} \rightarrow \mathrm{NH}+\mathrm{CHCl}_{2}
\end{gathered}
$$

Electron-induced decomposition

$$
\begin{aligned}
& \mathrm{e}+\mathrm{N}_{2} \rightarrow \mathrm{e}+\mathrm{e}+\mathrm{N}_{2}^{+} \\
& \mathrm{e}+\mathrm{O}_{2} \rightarrow \mathrm{e}+\mathrm{e}+\mathrm{O}_{2}^{+} \\
& \mathrm{e}+\mathrm{CCl}_{4} \rightarrow \mathrm{CCl}_{3}+\mathrm{Cl}^{-}
\end{aligned}
$$

lon-induced decomposition

$$
\mathrm{N}_{2}++\mathrm{CH}_{3} \mathrm{OH} \rightarrow \mathrm{CH}_{3}++\mathrm{OH}+\mathrm{N}_{2}
$$
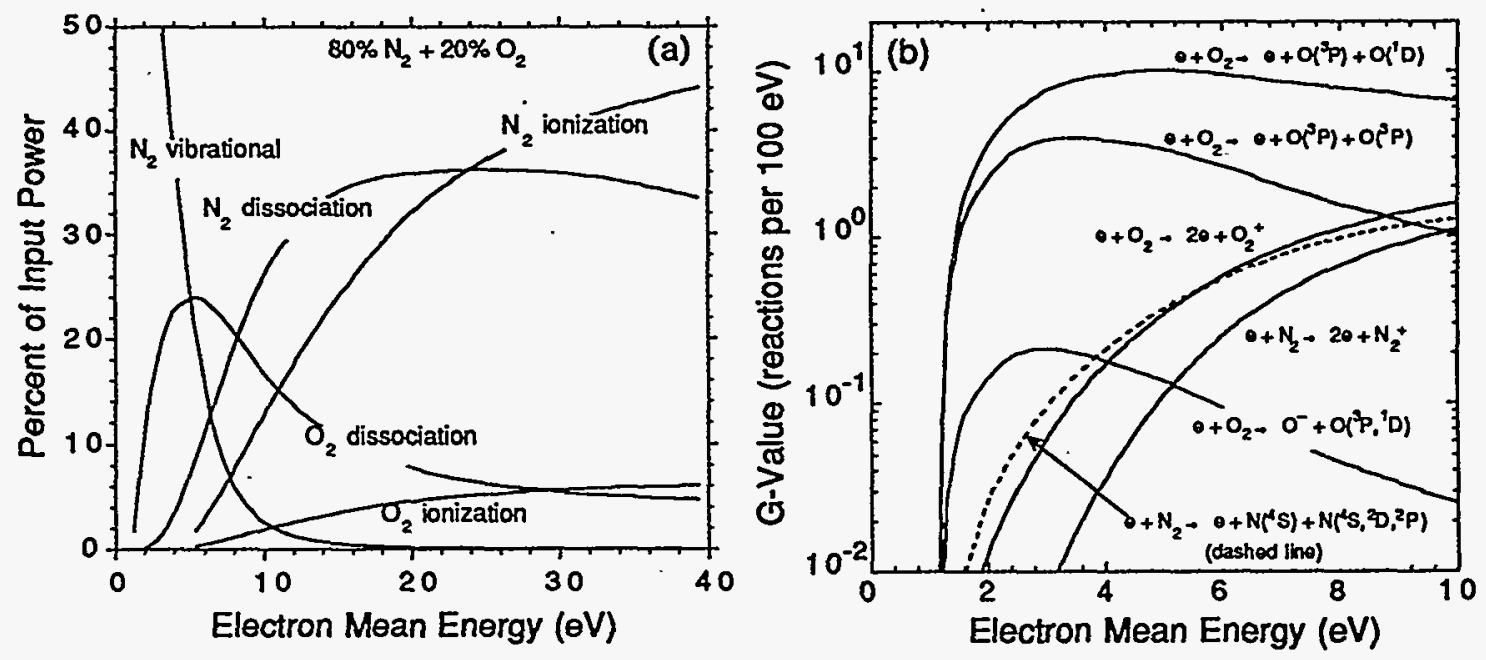

Figure 3. (a) Electrical power dissipation in a dry air discharge, showing the percent of input power consumed in the electron-impact processes leading to vibrational excitation, dissociation and ionization of $\mathrm{N}_{2}$ and $\mathrm{O}_{2}$. (b) Calculated G-values (number of reactions per $100 \mathrm{eV}$ of input energy) for dissociation and ionization processes in dry air, shown as functions of the electron mean energy in a discharge plasma. 

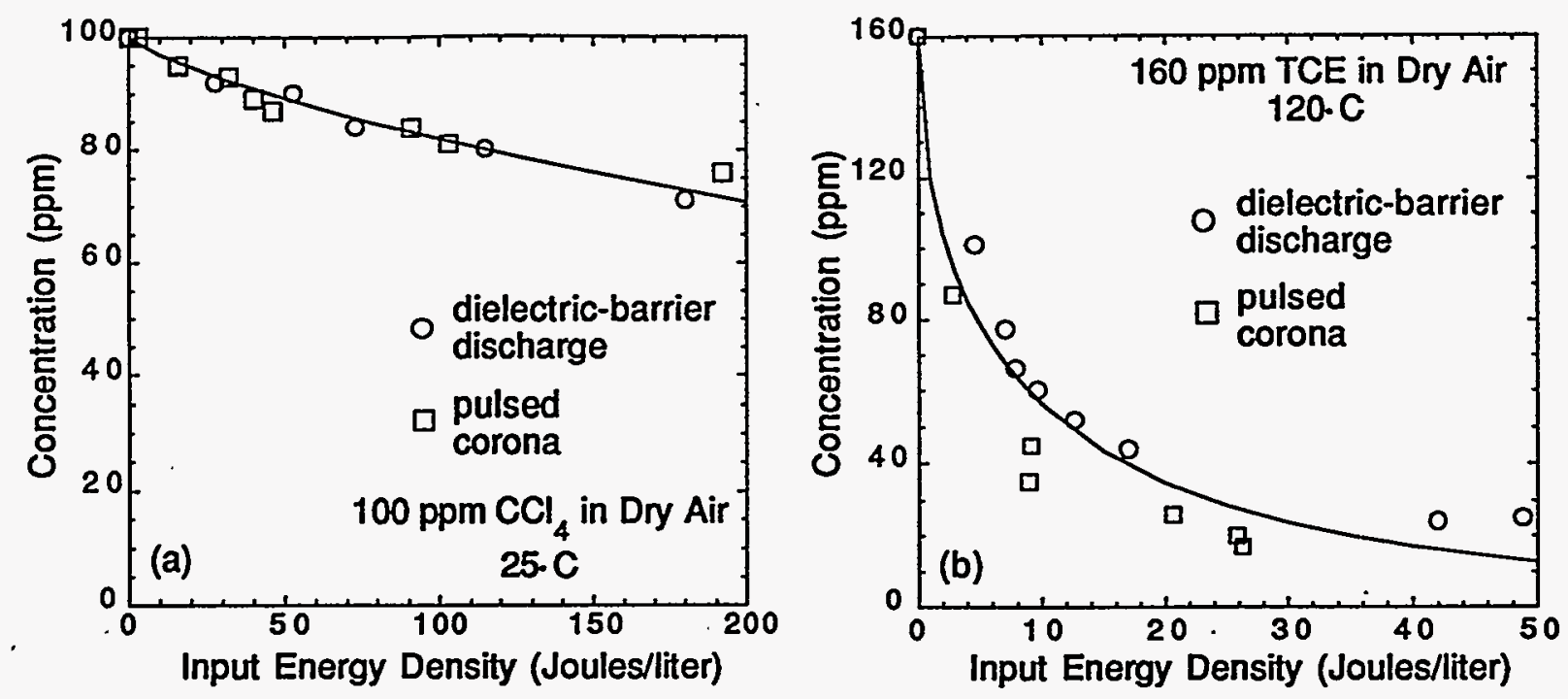

Figure 4. Pulsed corona and dielectric-barrier discharge processing of (a) $100 \mathrm{ppm}$ carbon tetrachloride in dry air at $25 . \mathrm{C}$ and (b) $160 \mathrm{ppm}$ trichloroethylene in dry air at 120 . C. There is no significant difference in the performance of different types of electrical discharge reactors.
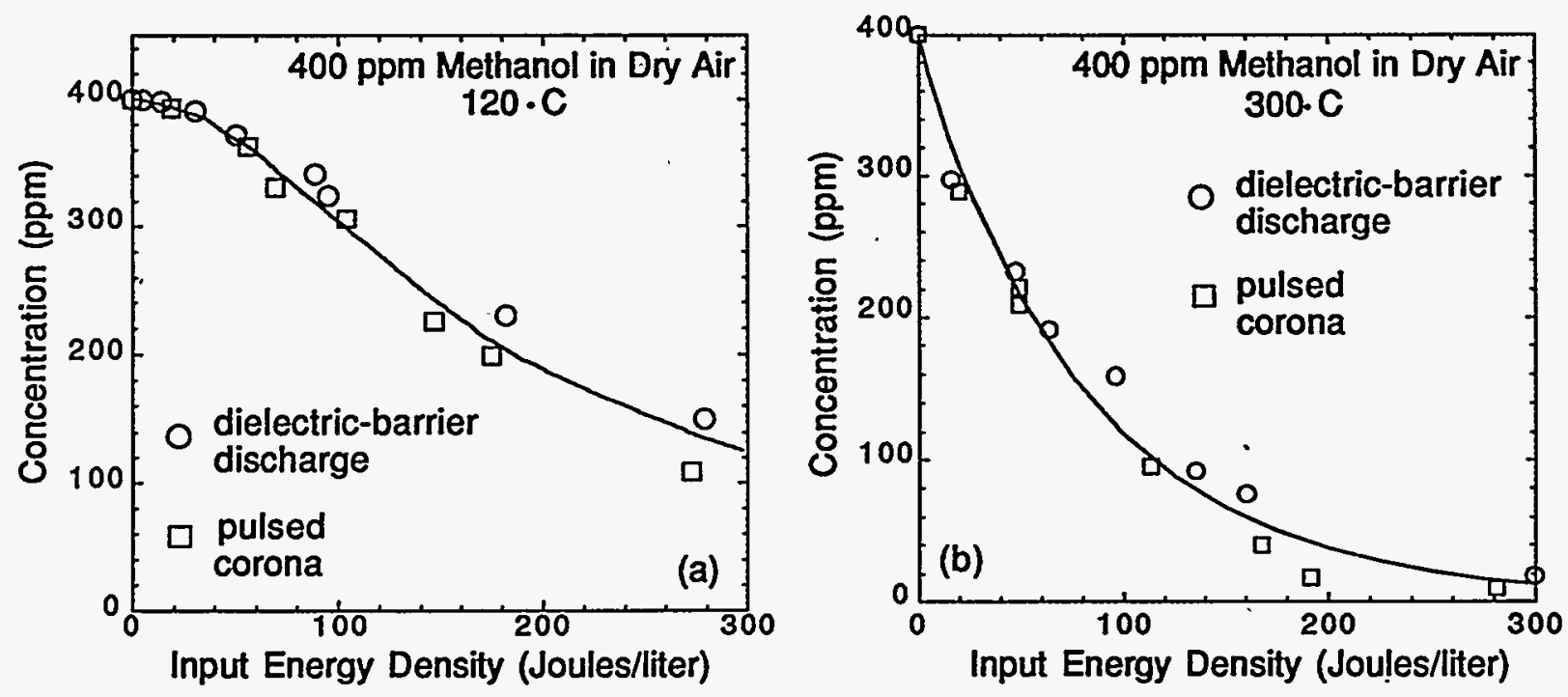

Figure 5. Pulsed corona and dielectric-barrier discharge processing of $400 \mathrm{ppm}$ methanol in dry air at (a) $120 . \mathrm{C}$ and (b) $300 . \mathrm{C}$. There is no significant difference in the performance of different types of electrical discharge reactors.

Under identical gas conditions (gas composition and gas temperature), we see no significant difference in the energy efficiency of various types of electrical discharge reactors. Figure 4-(a) shows the comparison between pulsed corona and dielectric-barrier discharge processing of carbon tetrachloride in dry air at $25 . \mathrm{C}$. Figure 4-(b) shows the comparison between pulsed corona and dielectric-barrier 
discharge processing of trichloroethylene in dry air at 120. C. Figures 5-(a) and 5-(b) shows the comparison between pulsed corona and dielectric-barrier discharge processing of methanol in dry air at $120 . \mathrm{C}$ and $300 . \mathrm{C}$. We now have considerable experimental evidence showing that all discharge reactors have the same energy consumption for identical gas conditions (Refs. 5,21).

Figure 6-(a) shows a comparison between electron beam, pulsed corona and dielectric-barrier discharge processing of $100 \mathrm{ppm}$ carbon tetrachloride $\left(\mathrm{CCl}_{4}\right)$ in dry air at $25 . \mathrm{C}$. The rate limiting step in the decomposition of $\mathrm{CCl}_{4}$ is determined by the dissociative attachment of $\mathrm{CCl}_{4}$ to the thermalized electrons in the created plasma (Refs. 16,17):

$$
\mathrm{e}+\mathrm{CCl}_{4} \rightarrow \mathrm{Cl}^{-}+\mathrm{CCl}_{3} \text {. }
$$

During the creation of the plasma, electron-ion pairs are produced through primary electron-impact ionization of the bulk molecules, such as $e+\mathrm{N}_{2} \Rightarrow e+\mathrm{N}_{2}+$ and $e+$ $\mathrm{O}_{2} \Rightarrow \mathrm{e}+\mathrm{O}_{2}{ }^{+}$, and the corresponding dissociative ionization processes for $\mathrm{N}_{2}$ and $\mathrm{O}_{2}$. An analysis of the rates of the reactions discussed above suggests that the energy consumption for $\mathrm{CCl}_{4}$ removal is determined by the energy consumption for creating electron-ion pairs. The energy density required to decompose $\mathrm{CCl}_{4}$ by $90 \%$ is around 20 Joules/liter and 1270 Joules/liter by electron beam and electrical discharge processing, respectively. This result demonstrates that for VOCs requiring copious amounts of electrons for decomposition, electron beam processing is much more energy efficient than electrical discharge processing. The main products in the plasma processing of $\mathrm{CCl}_{4}$ in air are $\mathrm{Cl}_{2}, \mathrm{COCl}_{2}$ and $\mathrm{HCl}$. These products can be easily removed from the gas stream; e.g. they dissolve and/or dissociate in aqueous solutions and combine with $\mathrm{NaHCO}_{3}$ in a scrubber solution to form $\mathrm{NaCl}$ (Ref. 22).
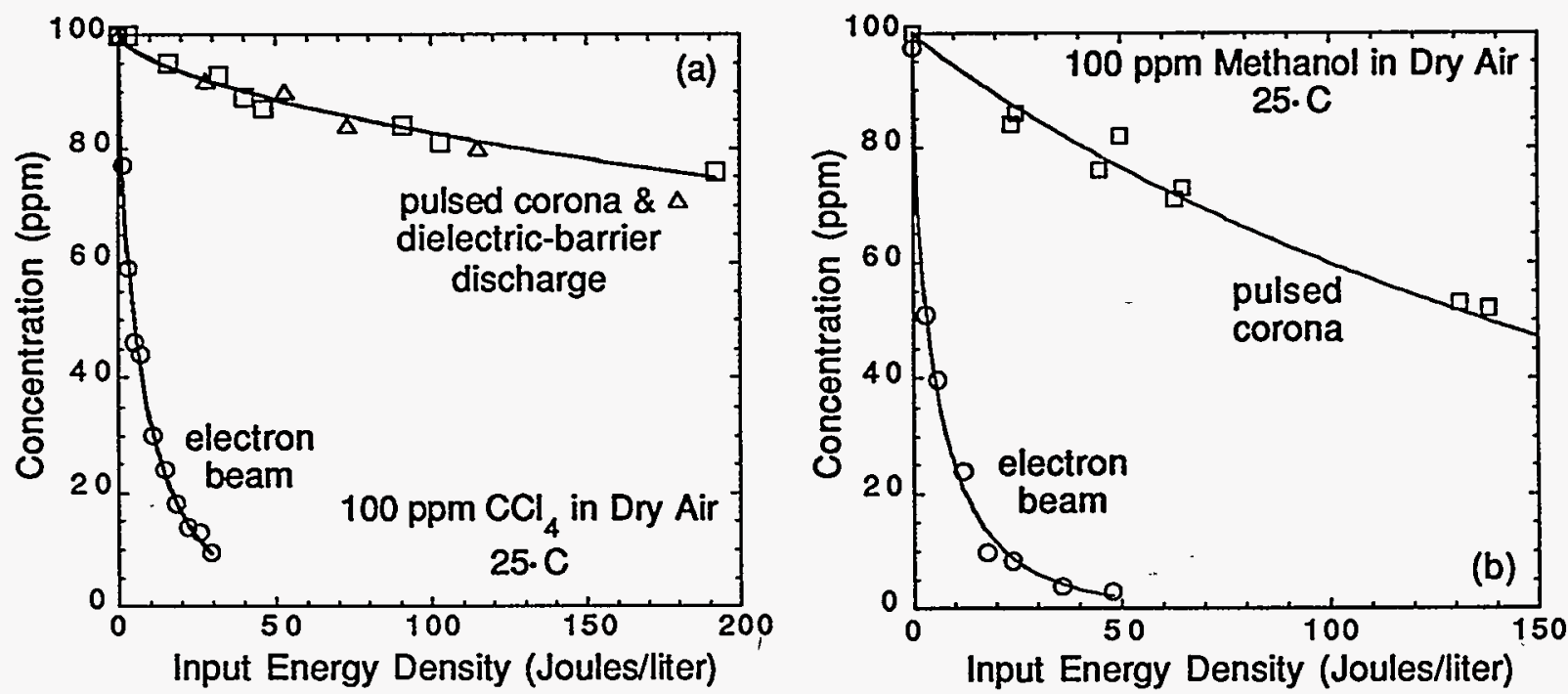

Figure 6. (a) Electron beam, pulsed corona and dielectric-barrier discharge processing of $100 \mathrm{ppm}$ carbon tetrachloride in dry air at $25^{\circ} \mathrm{C}$. (b) Electron beam and pulsed corona processing of $100 \mathrm{ppm}$ methanol in dry air at $25 . \mathrm{C}$. Electron beam processing is much more energy efficient compared to electrical discharge processing. 
Figure 6-(b) shows a comparison between electron beam and pulsed corona processing of $100 \mathrm{ppm}$ methanol in dry air at $25 . \mathrm{C}$. For the case of methanol, the electron beam method is more efficient because the decomposition proceeds mainly via a dissociative charge exchange reaction

$$
\mathrm{N}_{2}{ }^{+}+\mathrm{CH}_{3} \mathrm{OH} \rightarrow \mathrm{CH}_{3}{ }^{+}+\mathrm{OH}+\mathrm{N}_{2}
$$

The $\mathrm{OH}$ radicals resulting from the initial decomposition reaction (3) in turn may lead to additional decomposition of methanol via $\mathrm{OH}+\mathrm{CH}_{3} \mathrm{OH}$. To verify that the primary decomposition during electron beam processing does not proceed through an oxidation pathway using $O$ radicals, we performed the experiment using $\mathrm{N}_{2}$ as the background gas; the specific energy consumption for electron beam processing in dry air is almost identical to that in $\mathrm{N}_{2}$.

Not all compounds have strong dissociative electron attachment or dissociative ion charge exchange rates. Figure 7-(a) shows a comparison between electron beam and pulsed corona processing of $100 \mathrm{ppm}$ methylene chloride $\left(\mathrm{CH}_{2} \mathrm{Cl}_{2}\right)$ in dry air at 25. C. For methylene chloride, the dissociative attachment rate to electrons is many orders of magnitude lower compared to carbon tetrachloride. In this case, the electron beam method is also more efficient because the initial decomposition proceeds via a reaction with the $\mathrm{N}$ atom

$$
\mathrm{N}+\mathrm{CH}_{2} \mathrm{Cl}_{2} \rightarrow \text { products }
$$

The energy efficiency for dissociation of $\mathrm{N}_{2}$ to produce $\mathrm{N}$ atoms is much higher in an electron beam reactor.
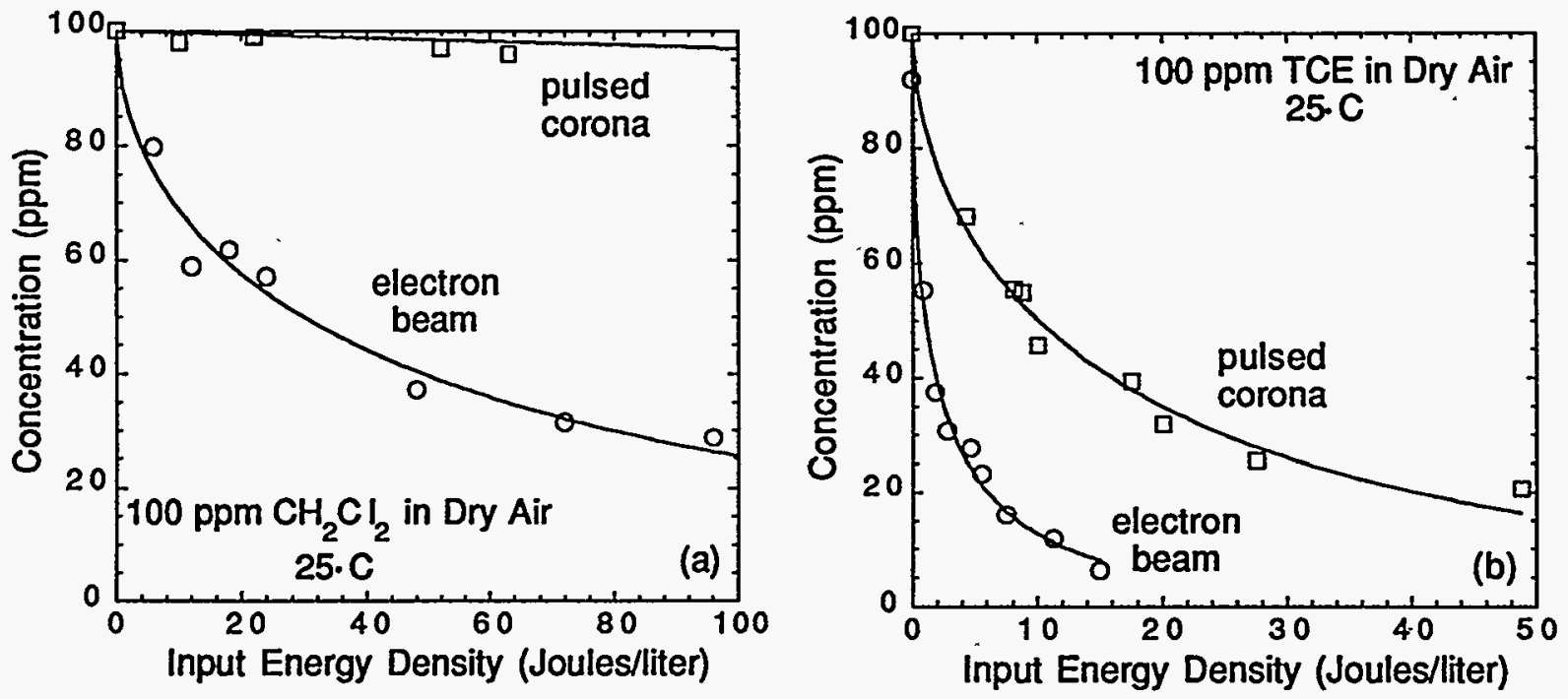

Figure 7. Comparison between electron beam and pulsed corona processing of 100 ppm of (a) methanol and (b) trichloroethylene in dry air at $25 . \mathrm{C}$. Electron beam processing is much more energy efficient compared to electrical discharge processing. 
For the case of trichloroethylene $\left(\mathrm{C}_{2} \mathrm{HCl}_{3}\right.$ or TCE), the initial decomposition pathway can proceed efficiently by reactions with either electrons (in the electron beam method) or $O$ radicals (in the electrical discharge method). Figure 7-(b) compares electron beam and pulsed corona processing of $100 \mathrm{ppm}$ trichloroethylene in dry air at $25 . \mathrm{C}$. The energy consumption for TCE removal is relatively small using either electron beam or electrical discharge methods. This is because of a chain reaction mechanism involving chlorine $(\mathrm{Cl})$ radicals. The reaction of TCE with electrons or $\mathrm{O}$ radicals initiates the detachment of $\mathrm{Cl}$ radicals. Other TCE molecules then decompose by $\mathrm{Cl}$ radical addition to the carbon-carbon double bond

$$
\mathrm{Cl}+\mathrm{CHClCCl}_{2} \rightarrow \text { products }
$$

The decomposition pathway (5) regenerates more $\mathrm{Cl}$ radicals; which react with other TCE molecules, causing a chain reaction. Our byproduct measurements and material balance analysis point to significant amounts of dichloroacetyl chloride (DCAC), phosgene, and hydrochloric acid in addition to smaller amounts of $\mathrm{CO}$ and $\mathrm{CO}_{2}$ in the effluent.

The case of trichloroethane $\left(\mathrm{C}_{2} \mathrm{H}_{2} \mathrm{Cl}_{3}\right.$ or TCA) is interesting in comparison to TCE. TCA and TCE have very similar electron attachment cross sections, yet the energy required for decomposition of TCE by electron beam processing is more than 10 times less than for TCA. The TCA molecule decomposes primarily through hydrogen abstraction by chlorine and oxygen radicals, whereas the TCE molecule decomposes through chlorine and oxygen radical addition to the carbon-carbon double bond. The carbon-carbon single bond in TCA is not susceptible to chlorine radical attack. The chain reaction mechanism possible with chlorinated ethylenes therefore does not occur with chlorinated ethanes (Ref. 15).

The above decomposition mechanisms provide examples of how the chemistry could strongly affect the economics of the process. In some cases it will be necessary to experimentally or theoretically obtain fundamental information on rate constants and branching ratios in order to understand the energy consumption and byproduct formation in the plasma process. Computer modeling of the plasma chemical kinetics serves as an important design tool for minimizing the energy consumption of the process and identifying all possible byproducts.

Tables I and II show why electron beam processing is much more effective than electrical discharge processing in decomposing VOCs. Table I shows a comparison of the calculated G-values (number of reactions per $100 \mathrm{eV}$ of input energy) for dissociation processes in dry air using an electron beam and a discharge reactor. Discharge plasma conditions are optimum for the dissociation of $\mathrm{O}_{2}$, whereas electron beam conditions are optimum for the dissociation of $\mathrm{N}_{2}$. Table II shows a comparison of the calculated G-values for ionization processes in dry air using an electron beam and a discharge reactor. The efficiency for production of electron-ion pairs is much higher in an electron beam reactor compared to that in electrical discharge reactor. 
Table I. Calculated G-values for dissociation processes in dry air using an electron beam and an electrical discharge reactor.

\begin{tabular}{|c|c|c|}
\hline ? & Electron Beam & olscharge \\
\hline$e+N_{2} \rightarrow e+N\left({ }^{4} S\right)+N\left({ }^{4} S, 2 D, 2 P\right)$ & 1.2 & 0.17 \\
\hline$e+O_{2} \rightarrow e+O(3 P)+O\left({ }^{3} P\right)$ & 1.3 & 4.0 \\
\hline$e+\mathrm{O}_{2} \rightarrow \mathrm{e}+\mathrm{O}\left({ }^{3} \mathrm{P}\right)+\mathrm{O}\left({ }^{1} \mathrm{D}\right)$ & 2.65 & 10.0 \\
\hline $\left.\mathrm{e}+\mathrm{O}_{2} \rightarrow \mathrm{O}^{-}+\mathrm{O}^{3} \mathrm{P}, 1 \mathrm{D}\right)$ & 0.11 & 0.19 \\
\hline
\end{tabular}

Table II. Calculated G-values for ionization processes in dry air using an electron beam and an electrical discharge reactor.

\begin{tabular}{|c|c|c|}
\hline REACTION" & Electron Beam: & Oiseriarge \\
\hline$e+N_{2} \rightarrow 2 e+N(4 S, 2 D)+N^{+}$ & 0.69 & $<10^{-6}$ \\
\hline$e+N_{2} \rightarrow 2 e+N_{2}+$ & 2.27 & 0.044 \\
\hline $\mathrm{e}+\mathrm{O}_{2} \rightarrow 2 \mathrm{e}+\mathrm{O}_{2}+$ & 2.07 & 0.17 \\
\hline$e+O_{2} \rightarrow 2 e+O^{(1 D} D+O^{+}$ & 1.23 & 0.0016 \\
\hline
\end{tabular}

\section{COST ESTIMATES}

Table III shows the comparison between pulsed corona and electron beam processing of various VOCs in dry air at room temperature. As mentioned previously, we observe no significant difference in the performance of pulsed corona and dielectric-barrier discharge reactors. For all the compounds we tested, electron beam processing is more energy efficient than either pulsed corona or dielectric-barrier discharge processing.

Assuming a nominal energy cost of 10 Joules/liter to decompose a mixture of volatile organic compounds from $100 \mathrm{ppm}$ to $10 \mathrm{ppm}$, the electron beam power required for an $80,000 \mathrm{cfm}$ total gas flow rate application is 380 kilowatts. Some commercial electron beam generators now cost as low as $\$ 2$ per beam watt. A 380 kilowatt electron beam system would therefore have a capital cost of $\$ 760,000$. This corresponds to a capital cost of less than $\$ 10$ per $\mathrm{cfm}$. This is cheaper than thermal oxidation methods that use advanced heat recovery. Similarly, the five year operating cost (based on $\$ 0.05 / \mathrm{kWh}$ electricity cost with 4,000 hours operation/year) is less than $\$ 5$ per cfin. Again the operating cost of the electron beam method is much lower than those of advanced thermal oxidation or carbon adsorption.

Straightforward engineering is the major advantage of electrical discharge methods. However, the electrical energy consumption of electrical discharge reactors are excessive, as can be deduced from Table III. If we assume that a pulsed corona or dielectric-barrier discharge reactor consumes only 5 times more energy per VOC 
molecule, i.e., 50 Joules/liter to decompose the VOC from $100 \mathrm{ppm}$ to $10 \mathrm{ppm}$, then the power required is 1.9 megawatts. Even though the capital cost for discharge reactors may be low, the operating costs over several years can greatly exceed the capital cost because of the large electrical energy consumption.

Table III. Comparison between pulsed corona and electron beam processing of 100 ppm VOC in dry air at room temperature. Energy density (Joules per standard liter) required for $90 \%$ decomposition of the VOC. Based on experimental data taken at Lawrence Livermore National Laboratory and First Point Scientific, Inc.

\begin{tabular}{|c|c|c|}
\hline 180 & Efloton Bean & pulsed corrona \\
\hline Trichloroethylene & 6 & 38 \\
\hline O-Xylene & 10 & 370 \\
\hline Ethylene & 15 & 83 \\
\hline Methanol & 15 & 450 \\
\hline Carbon Tetrachloride & 20 & 1277 \\
\hline Toluene & 34 & 1586 \\
\hline
\end{tabular}

Table IV shows nominal air pollution control costs using various VOC control technologies. An energy cost in the range of 10-30 Joules/liter was assumed to decompose $100 \mathrm{ppm}$ of VOC using electron beam processing. A pulsed corona or dielectric-barrier discharge reactor consumes at least 5 times more energy per VOC molecule. For the capital costs, it was assumed that $\$ 2 /$ watt for electron beam, $\$ 1 /$ watt for pulsed corona, and $\$ 0.20 /$ watt for dielectric-barrier discharge are required. The five year operating cost is based on $\$ 0.05 / \mathrm{kWh}$ electricity cost with 4,000 hours operation/year. For control of emissions from dilute, large volume sources of VOCs, this preliminary cost estimates show that

(1) the operating cost of electrical discharge methods such as pulsed corona or dielectric-barrier discharge is excessive, .

(2) the electron beam method is the preferable non-thermal plasma technique, and

(3) the electron beam method is cost-competitive to thermal and catalytic methods that employ heat recovery or hybrid techniques.

A realistic comparison between different VOC control technologies must include all factors. These include: (1) energy costs; (2) capital costs; (3) operating costs; (4) maintenance costs; (5) pollutant removal efficiency; (6) generation of secondary pollutants; (7) plugging/fouling/poisoning; (8) reliability/downtime; (9) safety; and (10) equipment life. 
Table IV. Cost comparison of various VOC control technologies for the case of a paint spray booth operating at a gas flow rate of $80,000 \mathrm{cfm}$ containing $70 \mathrm{ppm}$ MEK and $30 \mathrm{ppm}$ toluene.

\begin{tabular}{|c|c|c|c|}
\hline $4 \sqrt{4}$ System & Capitar cost? & Operating & $\begin{array}{l}\text { Total Evo } \\
\text { reat Cost }\end{array}$ \\
\hline $\begin{array}{c}\text { Regenerative Thermal } \\
\text { Oxidizer }\end{array}$ & $\$ 1,200,000$ & $\$ 240,000$ / year & $\$ 2,400,000$ \\
\hline $\begin{array}{c}\text { Carbon Concentrator + } \\
\text { Catalytic Oxidizer }\end{array}$ & $\$ 1,600,000$ & $\$ 54,000$ / year & $\$ 1,870,000$ \\
\hline Electron Beam & $\$ 760,000$ & $\$ 76,000$ / year & $\$ 1,140,000$ \\
\hline Pulsed Corona & $\$ 1,900,000$ & $\$ 380,000$ / year & $\$ 3,800,000$ \\
\hline $\begin{array}{c}\text { Dielectric-Barrier } \\
\text { Discharge }\end{array}$ & $\$ 380,000$ & $\$ 380,000$ / year & $\$ 2,280,000$ \\
\hline
\end{tabular}

${ }^{*}$ Assumes $\$ 2 /$ watt for electron beam, $\$ 1 /$ watt for pulsed corona, and $\$ 0.2 /$ watt for dielectricbarrier discharge.

**Based on $\$ 4 /$ million BTU fuel cost and $\$ 0.05 / \mathrm{kWh}$ electricity cost with 4,000 hours operation/year.

***Total capital cost plus five-year operating costs.

\section{CONCLUSIONS}

There are basically two types of non-thermal atmospheric-pressure plasma reactors: (1) electrical discharge reactors and (2) electron beam reactors. Many different variants of electrical discharge reactor have been proposed. Two of the more extensively investigated types of discharge reactors are based on the pulsed corona and dielectric-barrier discharge. The most mature discharge reactor is the dielectric-barrier discharge reactor used for ozone generation. However, the optimum conditions for ozone generation are not the optimum conditions for VOC destruction. There is now considerable experimental evidence showing that all discharge reactors have similar energy consumption under identical gas conditions. We have found that pulsed corona and other types of electrical discharge reactors are most suitable only for processes requiring $O$ radicals. For VOCs requiring copious amounts of electrons, ions, $\mathrm{N}$ atoms or $\mathrm{OH}$ radicals, the use of electron beam reactors is generally the best way of minimizing the electrical power consumption. Electron beam processing is remarkably more effective for all of the VOCs we tested. Cost analysis shows that the electron beam method is cost-competitive to thermal and catalytic methods that employ heat recovery or hybrid techniques.

\section{ACKNOWLEDGMENTS}

This work was performed in part at Lawrence Livermore National Laboratory under the auspices of the U.S. Department of Energy under Contract Number W- 
7405-ENG-48, with support from the Advanced Energy Projects Division of the Office of Energy Research. The electron beam processing equipment was developed under a National Science Foundation SBIR grant, Contract Number III-9122767.

\section{REFERENCES}

[1] B. Bertelsen, "Catalytic Control of VOC Emissions", Manufacturers of Emission Controls Association, Washington, DC, 1992, pp. 24-28.

[2] G. Leson and S. Dharmavaram, "A Status Overview of Biological Air Pollution Control", Paper \# 95-MP9A.01 presented at the 88th Annual Meeting \& Exhibition of the Air \& Waste Management Association, San Antonio, TX, June 18-23, 1995.

[3] A collection of papers on various types of non-thermal plasma reactors being investigated for VOC abatement appears in Non-Thermal Plasma Techniques for Pollution Control: Part A - Overview, Fundamentals and Supporting Technologies, edited by B. M. Penetrante and S. E. Schultheis (Springer-Verlag, Heidelberg, 1993) and Non-Thermal Plasma Techniques for Pollution Control: Part B - Electron Beam and, Electrical Discharge Processing, edited by B. M. Penetrante and S. E. Schultheis (Springer-Verlag, Heidelberg, 1993).

[4] T. Yamamoto, K. Ramanathan, P. A. Lawless, D. S. Ensor, J. R. Newsome, N. Plaks, G. H. Ramsey, C. A. Vogel, and L. Hamel, IEEE Trans. on Ind. Appl. 28, 528 (1992); T. Yamamoto, P. A. Lawless, M. K. Owen, D. S. Ensor, and C. Boss, in Non-Thermal Plasma Techniques for Pollution Control: Part B - Electron.Beam and Electrical Discharge Processing, edited by B. M. Penetrante and S. E. Schultheis (Springer-Verlag, Heidelberg, 1993) pp. 223-238.

[5] M. C. Hsiao, B. T. Merritt, B. M. Penetrante, G. E. Vogtlin, and P. H. Wallman, J. Appl. Phys. 78, 3451 (1995).

[6] D. Evans, L. A. Rosocha, G. K. Anderson, J. J. Coogan, and M. J. Kushner, J. Appl. Phys. 74, 5378 (1993); L. A. Rosocha, G. K. Anderson, L. A. Bechtold, J. J. Coogan, H. G. Heck, M. Kang, W. H. McCulla, R. A. Tennant, and P. J. Wantuck, in Non-Thermal Plasma Techniques for Pollution Control: Part B Electron Beam and Electrical Discharge Processing, edited by B. M. Penetrante and S. E. Schultheis (Springer-Verlag, Heidelberg, 1993) pp. 281-308.

[7] W. C. Neely, E. I. Newhouse, E. J. Clothiaux, and C. A. Gross, in Non-Thermal Plasma Techniques for Pollution Control: Part B-Electron Beam and Electrical Discharge Processing, edited by B. M. Penetrante and S. E. Schultheis (SpringerVerlag, Heidelberg, 1993) pp. 309-320; E. I. Newhouse, W. C. Neely, E. J. Clothiaux, and J. W. Rogers, in ACS Symposium on Emerging Technologies in Hazardous Waste Management VI, pp. 207-210; E. J. Clothiaux, J. A. Koropchak, and R. R. Moore, Plasma Chem. Plasma Process. 4, 15 (1984).

[8] M. E. Fraser, D. A. Fee, and R. S. Sheinson, Plasma Chem. Plasma Process. 5, 163 (1985); M. E. Fraser and R. S. Sheinson, Plasma Chem. Plasma Process. 6, 27 (1986).

[9] S. Masuda, in Non-Thermal Plasma Techniques for Pollution Control: Part B - 
Electron Beam and Electrical Discharge Processing, edited by B. M. Penetrante and S. E. Schultheis (Springer-Verlag, Heidelberg, 1993) pp. 199-210; T. Oda, T. Takahashi, H. Nakano, and S. Masuda, in Proceedings of the 1991 IEEE Industrial Application Society Meeting (Dearborn, MI, September/October 1991) pp. 734-739.

[10] A. Czernichowski and $\mathrm{H}$. Lesueur, in Proceedings of the 10th International Symposium on Plasma Chemistry (Bochum, Germany, 1991); A. Czernichowski and $\mathrm{T}$. Czech, in Proceedings of the 3rd International Symposium on High-Pressure Low-Temperature Plasma Chemistry (Strasbourg, France, 1991).

[11] L. J. Bailin, M. E. Sibert, L. A. Jonas, and A. T. Bell, Environ. Sci. Tech. 9, 254 (1975).

[12] R. C. Slater and D. H. Douglas-Hamilton, J. Appl. Phys. 52, 5820 (1981).

[13] H. Scheytt, H. Esrom, L. Prager, R. Mehnert, and C. von Sonntag, in NonThermal Plasma Techniques for Pollution Control: Part B - Electron Beam and Electrical Discharge Processing, edited by B. M. Penetrante and S. E. Schultheis (Springer-Verlag, Heidelberg, 1993) pp. 91-102.

[14] S. M. Matthews, A. J. Boegel, J. A. Loftis, R. A. Caufield, B. J. Mincher, D. H. Meikrantz, and R. J. Murphy, Radiat. Phys. Chem. 42, 689 (1993).

[15] S. A. Vitale, K. Hadidi, D. R. Cohn, P. Falkos and L. Bromberg, "Trichloroethylene and 1,1,1-Trichloroethane Decomposition in an Electron Beam Generated Plasma Reactor", paper presented at the I\&EC Special Symposium of the American Chemical Society, Atlanta, GA, September 17-20, 1995.

[16] L. Bromberg, D. R. Cohn, M. Kock, R. M. Patrick, and P. Thomas, Phys. Lett. A 173, 293 (1993); M. Koch, D. R. Cohn, R. M. Patrick, M. P. Schuetze, L. Bromberg, D. Reilly and P. Thomas, Phys. Lett. A 184, 109 (1993).

[17] B. M. Penetrante, M. C. Hsiao, B. T. Merritt, G. E. Vogtlin, P. H. Wallman, A. Kuthi, C. P. Burkhart and J. R. Bayless, Phys. Lett. A 209, 69 (1995).

[18] B. M. Penetrante, M. C. Hsiao, J. N. Bardsley, B. T. Merritt, G. E. Vogtlin, P. H. Wallman, A. Kuthi, C. P. Burkhart and J. R. Bayless, Pure \& Appl. Chem. (in press, 1996).

[19] H.-R. Paur, in Non-Thermal Plasma Techniques for Pollution Control: Part B Electron Beam and Electrical Discharge Processing, edited by B.M. Penetrante and S.E. Schultheis (Springer-Verlag, Heidelberg, 1993) pp. 77-90.

[20] B. Eliasson and U. Kogelschatz, J. Phys. B: At. Mol. Phys. 19, 1241 (1986).

[21] B. M. Penetrante, M. C. Hsiao, B. T. Merritt, G. E. Vogtlin and P. H. Wallman, IEEE Trans. Plasma Sci. 23, 679 (1995).

[22] R. M. Patrick and K. Hadidi, "An Electron Beam Plasma System for Halogenated Hydrocarbon Vapor Destruction", Paper \# 95-WP77B.04, 88th Annual Meeting \& Exhibition of the Air \& Waste Management Association, San Antonio, TX (18-23 June 1995). 